
4

\title{
Interaction Mechanisms of Antibiotic Sulfamethoxazole with Various Graphene-based Materials and Multiwall Carbon Nanotubes and the Effect of Humic Acid in Water
}

Fei Wang ${ }^{\mathrm{a}}$, Shuai Ma ${ }^{\mathrm{a}}$, Yang $\mathrm{Si}^{\mathrm{b}}$, Lifu Dong ${ }^{\mathrm{c}}$, Xilong Wang ${ }^{\mathrm{d}}$, Jun Yao ${ }^{\mathrm{a}, \mathrm{e}, *}$, Huilun Chen ${ }^{\mathrm{a}}$, Zhengji $\mathrm{Yi}^{\mathrm{a}}$, Wenchuo Yao ${ }^{\mathrm{a}}$, Baoshan Xing ${ }^{\mathrm{f}, * *}$

a School of Energy \& Environmental Engineering, and Beijing Key Laboratory of Resource-oriented Treatment of Industrial Pollutants, University of Science and Technology Beijing, 30 Xueyuan Road, 100083 Beijing, China

b PPSM, CNRS UMR 8531, ENS-Cachan, 61 av President Wilson, 94230 Cachan, France

c School of Environment and Energy, South China University of Technology, Guangzhou Higher Education Mega Centre, Guangzhou 510006, China

d Laboratory for Earth Surface Processes, College of Urban and Environmental Sciences, Peking University, Beijing 100871, China

e School of Water Resource and Environmental Engineering, Sino-Hungarian Joint Laboratory of Environmental Science and Health, China University of Geosciences (Beijing), 29 Xueyuan Road, Haidian District, 100083 Beijing, China

${ }^{\mathrm{f}}$ Stockbridge School of Agriculture, University of Massachusetts, Amherst, Massachusetts 01003 USA (1)

(1)
(1) 23

25

\section{Corresponding Author}

* Corresponding author. Tel.: (86) 10 62333305; fax: (86) 1062333305.

** Corresponding author. Tel.: (413) 545-5212; fax: (413) 545-3958.

E-mail addresses: yaojun@ustb.edu.cn (J. Yao), bx@umass.edu (B. Xing) 


\section{Abstract}

We studied the interaction mechanisms between carbonaceous nanomaterials (CNMs) and sulfamethoxazole (SMX) to elucidate their adsorption behaviors. Three graphene-based materials, reduced graphene oxide ( $\mathrm{rGO})$, graphene oxide $(\mathrm{GO})$, and graphene nanoplatelet pastes $(\mathrm{GNP})$, and five multiwalled carbon nanotubes (MWCNTs), MWCNT10, MWCNT15, MWCNT15-OH, MWCNT15-COOH, and N-doped MWCNTs, were used as sorbents. Oxygen-containing functional groups and graphene wrinkling suppressed SMX adsorption on GO and GNPs due to fewer Csp ${ }^{2}$ ring sites for $\pi-\pi$ stacking and fewer accessible flat surface adsorption sites, respectively. Ring current-induced ${ }^{1} \mathrm{H}$ NMR upfield chemical shifts increased as the $\pi$-donor concentration increased, as well as $\pi$-donor strength of polycyclic aromatic hydrocarbons (PAHs) (pyrene > phenanthrene > naphthalene) as model graphene compounds, suggesting that $\pi-\pi$ interaction strength of SMX with PAHs associated with $\pi$-donor strength. Moreover, ${ }^{1} \mathrm{H}$ NMR results further verified that carboxylic and hydroxyl groups in PAHs (9-phenanthrol and 3-phenanthrenecarboxylic acid) weakened the complexation between SMX and the graphitic surface. Additionally, the morphologies of rGO and MWCNT10 were observed using AFM, and transformed from being linear to scattered as the loading dose of the humic acid increased. Our results are useful to understand the distinct interaction mechanisms and subsequent adsorption behaviors resulting from various carbon nanomaterials with SMX in water. 


\section{Introduction}

The rapid advancement of nanoscience and nanotechnology, as well as the application extension of carbonaceous nanomaterials (CNMs), particularly graphene, have attracted increasing research attention of application in various fields $[1,2]$. The production of carbon nanotubes (CNTs) reached 4,600 t per annum (tpa) in 2011, and the estimated production of graphene will reach 1,200 tpa by 2019 [3]. Among the different types of CNMs, graphene and CNTs are developed most widely because of their superior physicochemical properties [4]. The presence of $\mathrm{sp}^{2}$ hybridized nanocarbons in these materials contribute to their outstanding features, which trigger the interest of both the scientific and technological communities [5]. Given their hydrophobicity and large surface area, graphene and CNTs are promising sorbents for removing various organic chemicals, such as aromatic amines, PAHs, and pesticides [6-10].

In contrast to CNTs, which were first reported in 1991 [11], graphene was only discovered in 2009 [12]. Hence, intensive studies are still needed to understand the interaction mechanisms between graphene and organic compounds. Although CNTs and graphene are both carbon-based nanomaterials, they are highly different nanomaterial entities, particularly in terms of shape (tubular vs. planar) and dimensions (1D vs. 2D). Their chemical properties (aqueous dispersibility and aggregation; e.g., stacking for graphene and bundling and tangling for CNTs) differ as well [4]. In addition, graphene oxides (GO) and reduced graphene oxides (rGO), which are two common members of the graphene family [13], typically possess a distinct range of functional groups, such as epoxy $(\mathrm{C}-\mathrm{O}-\mathrm{C})$, hydroxyl $(\mathrm{OH})$, and carboxylic $(\mathrm{COOH})$ groups, on their basal planes and edges [9]. These oxygen-containing functional groups also exist in CNTs [14]. These self-physicochemical characteristics can affect the adsorption behavior of CNMs for organic 
chemicals, which in turn may alter their transport and fate in the environment. However, limited systematic reports have been conducted on adsorption differences induced by the dissimilar characteristics of grapheme and CNTs. CNMs can be released into the environment from their products [15], and they have widely been detected from surface water, wastewater, sediments, and soil [16]. Once entering into the environment, which based on their current application is yet highly uncertain, CNMs are most likely to undergo various processes of surface modifications resulting from UV irradiation, microbial activity or interaction with natural organic matter. Moreover, industrial CNMs which widely applied in membranes and filtration system for water purification, thermal management, photodetectors, etc., are more typical than small amount of synthesized CNMs in research laboratories. Therefore, a systematic investigation must be conducted to reveal the differences in the adsorption behaviors of organic chemicals to various industrial CNMs.

Sulfamethoxazole (SMX), which is a commonly administered sulfonamide antibiotics, is widely used for human medicine and livestock production [17]. Often poorly metabolized and absorbed by humans and animals, SMX tends to enter into the aquatic environment [18-20]. Consequently, the environmental behavior of SMX has become a worldwide concern because of the potential proliferation of resistant pathogens [21]. Few works have been conducted to investigate the adsorption behaviors of SMX as an environmental contaminant to biochars [22], silica zeolites [23], carbon nanotubes [24, 25], sediment [26], and graphene oxide and graphite [27]. In these studies, $\pi-\pi$ electron donor-acceptor (EDA) interactions were identified as the main mechanism controlling adsorption. However, these reports merely mentioned $\pi-\pi$ EDA interactions lack of spectroscopic evidence for $\pi-\pi$ interactions. The present work will address this problem with direct measurements by proton nuclear magnetic resonance $\left({ }^{1} \mathrm{H}\right.$ NMR) [28]. In addition, oxygen on the CNMs could localize the $\pi$-electrons. Hence, whether functional groups $(\mathrm{OH}$ or $\mathrm{COOH})$ on the surface of $\mathrm{CNMs}$ 
affect $\pi-\pi$ interactions, and to what extent, still remain unclear. Therefore, $\pi-\pi$ EDA interaction, and the effect of $\mathrm{OH}$ or $\mathrm{COOH}$ on this interaction, must be elucidated to predict the potential environmental behavior of organic chemicals and various CNMs.

Dissolved organic matter (DOM) is an important aquatic component that significantly influences the adsorption of aromatic compounds [29], perfluoroalkyl acids [30], and carbamazepine [31] by acting as a competitor or modifying the surface properties of sorbents. Wang et al. reported that the adsorption of DOM masked numerous adsorption sites on MWCNTs, thereby reducing their adsorption for phenanthrene and 1-naphthol [29]. Similarly, SMX adsorption to CNTs was significantly reduced by the aggregation induced by DOM, but was increased as they were suspended as a result of stable dispersion [25]. These varying results indicate that tripartite interaction systems are complex: that organic compounds bind with DOM adsorbed on adsorbates; and that the morphology of CNMs alter with different coating degrees of DOM, which associate with the degree of suspended CNMs due to the varying strength of electric repulsion from polar functional groups on DOM. The literature, however, does not provide ample information as regards morphology change of CNMs with different coating degrees of DOM. Moreover, few studies have reported on the effect of DOM on the adsorption of antibiotics on graphenes.

The objectives of this study are as follows: (1) to investigate the adsorption distinction of SMX on GO, rGO, GNPs, and various MWCNTs with the use of batch techniques; (2) to demonstrate the interaction mechanisms by analyzing the characteristics of CNMs with the use of SEM/EDX, XPS, FTIR, ${ }^{1} \mathrm{H}$ NMR methods; and (3) to evaluate the effect of DOM on the adsorption of SMX to CNMs with the aid of AFM imaging.

\section{Experimental Section}




\subsection{Chemicals and Sorbents}

SMX, naphthalene (NAPH), phenanthrene (PHEN), pyrene (PYR), 9-phenanthrol, 3-phenanthrenecarboxylic acid, and HA was purchased from Sigma-Aldrich (St. Louis., MO, USA). Eight types of CNMs, namely, three graphene-based materials and five multiwalled CNTs (MWCNTs), which have distinct physical structures and chemical compositions, were used as sorbents. The three graphene-based materials were reduced graphene oxide (rGO), graphene oxide (GO), and graphene nanoplatelet pastes (GNP). The MWCNTs included MWCNT10 with an outer diameter of $<10 \mathrm{~nm}$, three multiwall CNT with an outer diameter in the range of $8-15 \mathrm{~nm}$ (MWCNT15, MWCNT15-OH, MWCNT15-COOH), and one N-doped MWCNTs with an outer diameter in the range of 30-50 nm. MWCNT10 was purchased from Shenzhen Nanotech Port Co., China. The other CNMs were purchased from Chengdu Organic Chemistry Co., Chinese Academy of Sciences. The physicochemical properties of the CNMs and SMX are summarized in Table S-1 and S-2 in the Supplementary Information (SI).

\subsection{Characterization of Carbonaceous Nanomaterials}

The surface morphology of CNMs was determined by using a Nova NanoSEM 450 (FEI Ltd., Holland), and the content of $\mathrm{C}$ and $\mathrm{O}$ in $\mathrm{CNMs}$ were semi-quantified with an energy dispersive X-ray (EDX) spectrum. The abundance of surface functional groups on CNMs was obtained by using an AXIS Ultra DLD X-Ray photoelectron spectrometer (Kratos Analytical Ltd., UK). The surface area and porosity of CNMs were measured by using adsorption-desorption isotherms of $\mathrm{N}_{2}$ at $77 \mathrm{~K}$ with a V-Sorb 2800P surface area and pore distribution analyzer (Gold APP Instruments Co., China). The surface characteristics of rGO with HA and SMX were investigated with a SEM/EDX after a part of the suspension containing rGO was air-dried. Four samples from the interaction 
systems with rGO and MWCNT10 containing 0.86 and $8.6 \mathrm{mg}$ C/L HA were scanned with an atomic force microscope (AFM) (5500, Agilent, USA). rGO and MWCNT10 without HA and SMX in suspension were set as control samples.

\subsection{Adsorption Experiments}

The batch equilibrium adsorption experiments of SMX to CNMs were conducted in aqueous solution, and performed in $15 \mathrm{~mL}$ glass vials with Telflon-lined screw caps at $25^{\circ} \mathrm{C}$. SMX was dissolved in methanol to prepare the stock solution. The methanol content in the adsorption systems was controlled to be below $0.1 \%(\mathrm{v} / \mathrm{v})$ to avoid cosolvent effect. The background solution contained $200 \mathrm{mg} / \mathrm{L} \mathrm{NaN}_{3}$ to minimize bioactivity and $0.02 \mathrm{M} \mathrm{NaCl}$ to maintain a constant ionic strength. The solid-to-liquid ratio for rGO was $2 \mathrm{mg}$ per $15 \mathrm{~mL}$ aqueous solution, whereas that for GO, GNPs, MWCNT10, MWCNT15, MWCNT15-OH, MWCNT15-COOH, and N-doped MWCNT was 7 mg per $15 \mathrm{~mL}$ aqueous solution. The isotherm experiments were performed on a rotary shaker at 100 rpm for 5 days. After equilibration, the solution was filtered through a $0.2 \mu \mathrm{m}$ PTFE filter. The filtrate was quantified at $265 \mathrm{~nm}$ with a Shimadzu LC20AD high-performance liquid chromatograph (HPLC) in conjunction with a SPD-20A UV detector (Kyoto, Japan), equipped with a reversed-phase C8 column $(5 \mu \mathrm{m}, 4.6 \mathrm{~mm} \times 150 \mathrm{~mm})$. The mobile phase was 40:60 (v:v) of acetonitrile and deionized water with $0.1 \%$ acetic acid, and the flow rate was $1 \mathrm{~mL} / \mathrm{min}$ [25]. All samples were run in duplicates. In view of the negligible mass loss $(<3.0 \%)$ of the adsorbate during the experiment, the adsorbed amount to the CNMs was calculated from the mass balance.

The HA stock solution was prepared according to the procedure in a previous work [32]. The final HA solution was analyzed with a high-temperature TOC instrument, and a concentration of $43.3 \mathrm{mg} \mathrm{C} / \mathrm{L}$ was obtained. The HA stock solution was stored in the dark at $4{ }^{\circ} \mathrm{C}$ prior to use. The 
effect of HA on the adsorption of SMX on CNMs was performed at a given concentration of 7 mg/L SMX. The initial concentrations of HA were 0.86-34.4 mg C/L.

The initial and equilibrium $\mathrm{pH}$ values of a interaction system in the absence and presence of HA were determined, and presented in Table S-3.

\subsection{Interaction of HA and SMX}

The binding of HA and SMX in the solution was assessed by fluorescence quenching technique [33]. The concentration of SMX was fixed at $10 \mathrm{mg} / \mathrm{L}$, and the HA concentration was adjusted to be within the range of $0.0-4.3 \mathrm{mg} \mathrm{C} / \mathrm{L}$. Their mixtures were thoroughly mixed for $24 \mathrm{~h}$ in the dark at room temperature. Then, the fluorescence of SMX was measured on a Hitachi F4500 spectrofluorometer (Tokyo, Japan). The excitation wavelength $\left(\lambda_{\mathrm{ex}}\right)$ was $275 \mathrm{~nm}$, and the emission $\left(\left(\lambda_{\text {em }}\right)\right.$ spectra were recorded at $220-550 \mathrm{~nm}$. The excitation and emission slits were $5 \mathrm{~nm}$, and the detector voltage was $700 \mathrm{~V}$. The fluorescence intensities at $\lambda_{\text {ex }} / \lambda_{\text {em }}$ of $275 / 340 \mathrm{~nm}$ without HA $\left(F_{0}\right)$ and with $\mathrm{HA}(F)$ were measured. The Stern-Volmer plot, $F_{0} / F=1+K_{\mathrm{SV}}[\mathrm{HA}]$, was constructed, where $K_{\mathrm{SV}}$ is the Stern-Volmer constant and [HA] is the concentration of HA [34].

\section{5. ${ }^{1} \mathrm{H}$ NMR Analysis of Complexation in the Solution}

The proton nuclear magnetic resonance ( $\left({ }^{1} \mathrm{H}\right.$ NMR) spectra of SMX as $\pi$-acceptor were recorded in methanol- $d_{4}$ (Acros) in mixture with model $\pi$-donor compounds (naphthalene, phenanthrene, pyrene, 9-phenanthrol, and 3-phenanthrenecarboxylic acid) at room temperature on a Bruker-400 MHz nuclear magnetic resonance (NMR) spectrometer (Bruker, Switzerland). The spectrometer was locked on the deuterium of the solvent, and the chemical shift $(\delta)$ was internally referenced to the $-\mathrm{CH}_{3}$ of SMX. 


\subsection{Data Analysis}

192

193

194

The Langmuir and Freundlich models were used to fit the equilibrium adsorption isotherm data of SMX by CNMs. Additional details these regarding models are presented in the SI. The distribution coefficient, $K_{\mathrm{d}}(\mathrm{L} / \mathrm{g})$, was calculated by dividing the adsorbed amount of the sorbate $\left(q_{\mathrm{e}}\right)$ by its equilibrium concentration in aqueous phase $\left(C_{\mathrm{e}}\right), K_{\mathrm{d}}=q_{\mathrm{e}} / C_{\mathrm{e}}$.

\section{Results and Discussion}

\subsection{Characteristics of the Sorbents}

SEM images revealed that GO, rGO, and GNP tended to stack into few layers, and that they acted like typical crumpled wave-like sheets to form groove regions (Fig. 1). rGO had slight aggregation with loose wrinkles. Compared to rGO, GO and GNP displayed relatively flat surfaces, especially GNP, which possessed the lowest pore volume of $0.06 \mathrm{~cm}^{3} / \mathrm{g}$. These grooves and surfaces are potential adsorption sites. By contrast, CNTs tend to form bundles or aggregates driven by van der Waals forces along the length axis because of their high hydrophobicity (Fig. S1). As reported in a previous study [35], the surface, groove, interstitial, and inner areas on CNTs offer adsorption sites for organic chemicals. Except for GO (43.41\%), the O content of other CNMs was relatively low (1.93 to $4.95 \%$ ) (Table S-1). The introduction of O-functional groups disrupted the $\pi$ electronic system of the graphene layer as a result of $\mathrm{sp}^{2} \rightarrow \mathrm{sp}^{3}$ rehybridization, which breaks up the delocalized $\pi$ band structure of graphene and acts as a scattering center in the graphene lattice [36, 37]. The vast differences in the BET surface area (SA) of CNMs (ranging from $9.93 \mathrm{~m}^{2} / \mathrm{g}$ to 530 $\mathrm{m}^{2} / \mathrm{g}$ ) are associated with their adsorption capacity. 
Several oxygen-containing functional groups were identified at the surfaces of GO, rGO, GNP, and N-doped MWCNT, as revealed by the FTIR spectra (Fig. S2). The spectra displayed a number of peaks. In particular, the broad peak at $\sim 3500 \mathrm{~cm}^{-1}$ represented the bonded hydroxyl of phenol groups [22], and the peaks at 1721,1593 , and $1034 \mathrm{~cm}^{-1}$ were attributed to the stretching vibration of $\mathrm{C}=\mathrm{O}$, aromatic $\mathrm{C}=\mathrm{C}$, and asymmetric stretch of $-\mathrm{COO}^{-}$, respectively $[38,39]$. The FTIR spectra of MWCNT10, MWCNT15, MWCNT15-OH, and MWCNT15-COOH have been reported in our previous studies $[32,35]$, where these functional groups were included as well.

The surface functional groups of CNMs were analyzed by using XPS (Fig. 2 for C 1s, Fig. S3 for the wide scan, Fig. S4 for O 1s, and Fig. S5 for N 1s). The eight CNMs presented a conspicuously high peak at $\sim 284.8 \mathrm{eV}$ because of the $\mathrm{sp}^{2}$-hybridized carbons in $\mathrm{C}=\mathrm{C} / \mathrm{C}-\mathrm{C}[40,41]$. Expect for $\mathrm{GO}$, a small peak at $\sim 285.9 \mathrm{eV}$ on other CNMs was attributed to $\mathrm{C}-\mathrm{O}$. However, only GO had a secondary peak at $287 \mathrm{eV}$, which indicated the presence of $\mathrm{C}=\mathrm{O}$ [38], suggesting that $\mathrm{GO}$ was more hydrophilic than the rest. According to the intensity, rGO, GO, MWCNT15-COOH possessed a relatively higher content of the $\mathrm{O}-\mathrm{C}=\mathrm{O}$ group at $289 \mathrm{eV}$, but it was not detected from GNP and MWCNT10. As for the $\mathrm{O} 1 \mathrm{~s}$ spectra, the peaks at $\sim 533.4$ and $\sim 532.08 \mathrm{eV}$ were attributed to -C-O/-OH groups and $\mathrm{C}(\mathrm{O}) \mathrm{O} /-\mathrm{C}=\mathrm{O}$, respectively [42]. The $\mathrm{N} 1 \mathrm{~s}$ spectra of N-doped MWCNT can be deconvoluted into pyridinic $\mathrm{N}$ at $398.47 \mathrm{eV}$, pyrrolic $\mathrm{N}$ at $399.33 \mathrm{eV}$, graphitic $\mathrm{N}$ at $400.19 \mathrm{eV}$, and oxidized $\mathrm{N}$ at $401.6 \mathrm{eV}$ [43-45]. Pyridine-like and pyrrole-like $\mathrm{N}$ may contribute to the $\pi$-conjugated system with a pair of p-electrons in the graphene layers [44].

\section{Fig.2}

\subsection{Adsorption of SMX on CNMs}

The adsorption isotherms of SMX on rGO, GO, GNPs, MWCNT10, MWCNT15, MWCNT15-OH, 
MWCNT15-COOH, and N-doped MWCNT are shown in Fig. 3. In general, the isotherms were fitted slightly better with the Freundlich rather than the Langmuir model; the regression parameters are listed in Table 1. Freundlich $n$ values indicate the heterogeneity of the CNMs, and a lower $n$ value is indicative of a heterogeneous surface with a wider adsorption site energy distribution [46]. According to $n$ values, the heterogeneity of CNMs followed this order: $\mathrm{rGO}>\mathrm{MWCNT10}>$ N-doped MWCNT $>$ GO > MWCNT15 = MWCNT15-COOH $>$ GNPs $>$ MWCNT15-OH.

\section{Fig.3 and Table 1}

In order to compare the adsorption affinity for these CNMs at a specific concentration, the single point $K_{\mathrm{d}}$ was calculated at $C_{\mathrm{e}}=2 \mathrm{mg} / \mathrm{L}$ according to the fitting results of the Freundlich model (Table 1). The $K_{\mathrm{d}}$ values followed this order: $\mathrm{rGO}>$ MWCNT10 > MWCNT15 > MWCNT15-COOH > N-doped MWCNT > MWCNT15-OH > GO > GNPs. Compared with Freundlich $n$ values order, heterogeneity of the CNMs closely associated with adsorption affinity of rGO and MWCNT10 (Fig. S6). Their adsorption affinity decreased with decrement of $n$ values. However, when $n$ values were greater than $0.6, K_{\mathrm{d}}$ kept the similar values. It means that the role of heterogeneous surface of MWCNT15, MWCNT15-COOH, N-doped MWCNT, MWCNT15-OH, GO and GNPs became limited for adsorption.

The physical properties of CNTs play important roles in the adsorption of organic contaminants [47]. Both graphene and CNTs are hydrophobic and primarily made up of $\mathrm{sp}^{2}$ carbon atoms densely parked in a hexagonal honeycomb crystal lattice. Therefore, the hydrophobic properties and the $\mathrm{sp}^{2}$ structure suggest that hydrophobic and $\pi-\pi$ interactions occur between CNMs and SMX. However, graphene can be converted from planar sheets into wrinkled and scrolled sheets [48], and CNTs can form bundles of randomly tangled individual tubes by means of aggregation [49]. The morphological changes of CNMs would alter the energy distribution of their adsorption sites, which 
in turn may influence the adsorption behaviors of SMX. For example, Bai et al. found that rGO with varying wrinkling associated with their adsorption rate [50]. As such, rGO, GO, and GNP exhibited different stacking structures because of their distinct wrinkling degrees (Fig. 1), resulting in different pore size distributions (Table S-1). rGO showed a high wrinkling degree, leading to large values of SA $\left(530 \mathrm{~m}^{2} / \mathrm{g}\right)$ and pore volume $\left(2.19 \mathrm{~cm}^{3} / \mathrm{g}\right)$. By contrast, GNP are stacked tightly to form the flake structure, and resulting in a weak wrinkling degree. GNP possessed the lowest values of SA $\left(9.93 \mathrm{~m}^{2} / \mathrm{g}\right)$ and pore volume $\left(0.06 \mathrm{~cm}^{3} / \mathrm{g}\right)$, and showed the lowest adsorption of SMX. As for GO, smooth nanosheets were exfoliated and dispersed in water because of the abundant $\mathrm{OH}$ and $\mathrm{COOH}$ groups (Fig. S2). As opposed to high SA of GO $\left(329 \mathrm{~cm}^{3} / \mathrm{g}\right)$, GO presented a very low adsorption affinity. Therefore, other interaction mechanisms aside from the varying physical structures of CNMs affected the adsorption behavior of CNMs and SMX.

The relationship between SA and $K_{\mathrm{d}}$ was plotted to further clarify the influence of the surface area of CNMs on SMX adsorption. The relationship was generally linear after GO was removed (Fig. S7), suggesting that SA played an important role in the adsorption of SMX on CNMs. Meantime, surface area-normalization reduced the difference in adsorption affinity (Fig. S8), but the normalized isotherms were still scattered, suggesting other interactions occurred.

To focus on molecular interaction mechanisms aside from the hydrophobic effect, the normalized adsorption coefficient $\left(K_{\mathrm{d}} / K_{\mathrm{HW}}\right)$ of $\mathrm{SMX}$ on $\mathrm{CNMs}$ was calculated at different equilibrium concentrations $\left(C_{\mathrm{e}}\right)$ (Fig. S9). Hexadecane is a nonpolar organic solvent that is useful for examining intermolecular interactions (e.g., $\pi-\pi$ interaction) in addition to hydrophobicity effect $[47,51]$. The aromatic ring of SMX is an effective $\pi$-electron acceptor because of the attracting electron of electron-withdrawing sulfuric groups [22], and CNMs can serve as $\pi$-eletron donors. The distinct $K_{\mathrm{d}} / K_{\mathrm{HW}^{-}} C_{\mathrm{e}}$ plots indicated the different $\pi-\pi$ interaction strength of a nanomaterial with SMX 
molecules, and higher $K_{\mathrm{d}} / K_{\mathrm{HW}}$ values indicated stronger interaction. So, $\pi$ - $\pi$ interaction was one of other mechanisms for SMX adsorption on CNMs.

The dominated species of SMX were cationic, neutral, and anionic at $\mathrm{pH}<1.7$, around 3.7, and $>$ 5.7, respectively [52]. Anionic SMX species increased with increment of solution $\mathrm{pH}$. The $\mathrm{pH}$ of interaction systems were around 7 , expect for $\mathrm{GO}(\mathrm{pH}=4.83)$ (Table S-3). Subsequently, the electrostatic repulsion occurred between SMX and CNMs. Considering the high oxygen content of GO, electrostatic repulsion should be one of main interaction mechanism to greatly decrease adsorption of SMX on GO. As for other CNMs with low oxygen content, electrostatic repulsion was not enough strong to alter the general adsorption of SMX.

H-bond interaction of $\mathrm{NH}_{2}$ group in $\mathrm{SMX}$ with O-containing functional groups on $\mathrm{CNP}$ should happened. However, considering the low adsorption affinity of SMX with GO and low percent of oxygen content of other CNMs, H-bond interaction was not the key interaction in our interaction systems.

\subsection{Effects of O-containing Functional Groups on the adsorption of SMX on CNMs and}

\section{Spectroscopic Studies of the $\pi-\pi$ Interaction in Solution}

GO, MWCNT15-OH, and MWCNT15-COOH exhibited a low adsorption compared with that of CNMs with the same structures, such as rGO and MWCNT15. This low adsorption may be attributed to the O-containing functional groups. Aside from reducing the hydrophobicity of CNMs to decrease their adsorption for SMX, the effects of O-containing functional groups on $\pi-\pi$ interaction also altered the adsorption of CNMs for SMX.

The $\pi$ - $\pi$ EDA interaction between SMX ( $\pi$-electron acceptor) and aromatic compounds (as models of $\pi$-electron donors on graphene surfaces), as well as the effects of O-containing functional 
groups $(\mathrm{OH}$ and $\mathrm{COOH})$ on $\pi-\pi$ interaction, was further tested by performing liquid phase ${ }^{1} \mathrm{H}$ NMR experiments. As a nucleus was placed above or below the plane of an aromatic structure, electronic shielding would occur because of the "ring effect" [53]. Thus, upfield NMR chemical shifts $(\delta)$ induced by ring current effect can be used to support the "face-to-face" geometry of the $\pi-\pi$ EDA complex. The ${ }^{1} \mathrm{H}$ NMR up-field shift was clearly observed for SMX $\left(-\mathrm{CH}_{3}\right.$ group on the N-heterocyclic moiety) in the mixture with PAHs (Fig. 4). The shift increased as the $\pi$-donor concentration increased, as well as $\pi$-donor strength of PAHs (pyrene $>$ phenanthrene $>$ naphthalene) $[28,54]$. Meanwhile, $\mathrm{OH}$ (9-phenanthrol) and $\mathrm{COOH}$ (3-phenanthrenecarboxylic acid) can reduce the $\pi-\pi$ EDA interaction strength, particularly for 3-phenanthrenecarboxylic acid, whose ${ }^{1} \mathrm{H}$ NMR chemical shift did not change as the concentration increased. It also was reported that oxygen on the surface of CNMs localizes the $\pi$-electrons, reducing the $\pi-\pi$ interactions between the graphitic surface and benzene rings of aromatic organic chemicals [47]. Therefore, O-containing functional groups altered the adsorption of CNMs by reducing the hydrophobicity of CNMs and weakening the $\pi-\pi$ interaction. Hence, the oxygen content of CNMs was responsible for the adsorption behavior.

Fig.4

The oxygen content of $\mathrm{GO}$ reached up to $43.41 \%$, which is much higher than that of MWCNT15-OH (4.15\%), MWCNT15-COOH (4.95\%), and other CNMs (<4.0\%). The effect of oxygen became obvious at high oxygen content of CNMs. This contributed to the low adsorption of GO for SMX ( $\left.q_{\max } 0.15 \pm 0.02 \mathrm{mg} / \mathrm{g}\right)$, which is much lower than the adsorption capacity of $240 \mathrm{mg} / \mathrm{g}$ to SMX on GO (no data on oxygen content ) reported by Chen et al., [22]. The huge differences possibly resulted from the amount of surface oxygen content. As the surface oxygen content of the MWCNTs increased, the adsorption of tetracycline increased to the maximum values $(\mathrm{O} \%$, 
2.0-3.2\%) and then decreased $(\mathrm{O} \%, 3.2-5.9 \%)$ [55]. According to the effects of oxygen content on the adsorption of MWCNTs with similar SA (approximate $140 \mathrm{~m}^{2} / \mathrm{g}$ ), the adsorption to SMX followed this order: MWCNT15 (3.43\%) > MWCNT15-COOH (4.15\%) > MWCNT15-OH (4.95\%). It was because of that water cluster formation played a more important role in SMX adsorption than did dispersion, and thus the adsorption affinity for SMX decreased with the increasing oxygen content [55]. However, for the adsorption of N-doped MWCNT with low oxygen content $(1.93 \%)$ and SA $\left(52.9 \mathrm{~m}^{2} / \mathrm{g}\right), \mathrm{N}$-doping may enhance $\pi$ - $\pi$ interaction to maintain a higher adsorption than that of MWCNT15-OH. The reason is that the effective site of the $\mathrm{sp}^{2}$ carbon of CNMs has abundant free-flowing $\pi$-electrons, which can be activated by conjugating with the long-pair electrons from the doped $\mathrm{N}$ atoms [43].

\subsection{Effect of Dissolved Humic Acid}

The effects of HA addition on the adsorption of SMX on CNMs were shown in Fig. 5. As HA concentration was increased from $0.86 \mathrm{mg} \mathrm{C} / \mathrm{L}$ to $34.4 \mathrm{mg} \mathrm{C} / \mathrm{L}, K_{\mathrm{d}}$ initially decreased sharply and then smoothly because of the competition with HA and the distribution of SMX to free HA. HA could interacted with CNMs by hydrophobic, $\pi-\pi$, H-bonding and electrostatic interactions due to HA containing the aromatic fractions and O-containing functional groups (carboxyl and phenolic groups) $[32,56]$. But, these interactions depended on the solution $\mathrm{pH}$. As reported, DOM adsorption decreased with increasing $\mathrm{pH}$ due to electrostatic repulsive forces between negatively charged carboxylic acid functional groups on the O-MWCNT and NOM at $\mathrm{pH}$ 7, but the hydrophobic $\pi-\pi$ was still dominant [57]. As for this study, the initial and equilibrium $\mathrm{pH}$ of interaction systems containing CNMs was around 7, except for $\mathrm{GO}(\mathrm{pH}$, around 4.5) (Table S-3). Hence, the electrostatic repulsion should be similar for $\mathrm{CNMs}$ due to the similar $\mathrm{pH}$ of solution and low 
oxygen content of CNMs. Whereas, negative chargers of GO and HA were smaller at lower pH than that at higher $\mathrm{pH}$. Therefore, electrostatic repulsion between $\mathrm{GO}$ and $\mathrm{HA}$ should not be strong as well. Subsequently, HA could adsorbed on CNMs and competed adsorption sites on CNMs with SMX. Beside competition adsorption, free HA could bind SMX molecules with the Stern-Volmer constant $\left(K_{\mathrm{SV}}\right)$ of $9 \times 10^{4} \mathrm{~L} / \mathrm{kg}$ (Fig. S10). Thus, part of free SMX may bind again with the adsorbed HA on CNMs in the adsorption system. But, considering the deceasing adsorption of SMX with the increasing HA concentration, the binding interaction between SMX and HA should be weak.

\section{Fig.5}

As shown in the AFM images, with HA concentrations varying between 0.86 and $8.6 \mathrm{mg} \mathrm{C} / \mathrm{L}$ (Fig. 6 and Fig. S11), the thickness of rGO and MWCNT10 did not substantially increase, and the thickness was similar under the same concentrations of rGO and MWCNT10 (Fig. 6C, 6E, 6G, and $6 \mathrm{~J})$. It indicates that the adsorption thickness of HA on CNMs tends to be a specific value and independent on the HA concentration. Another interesting phenomenon is that linear CNMs were observed (Fig. 6B and 6G), and few CNMs were scattered at $0.86 \mathrm{mg} \mathrm{C} / \mathrm{L}$ (Fig. 6C and 6H). However, CNMs became dispersed particles at $8.6 \mathrm{mg} \mathrm{C} / \mathrm{L}$. The different morphologies of CNMs at two HA concentrations suggested that, as the HA level was low, it did not cover the entire CNP surface. The presence of HA was not enough to disperse CNMs by disrupting the strong van der Waals forces between CNP particles driven by electrostatic repulsion and steric hindrance of HA. The driven forces increased as the HA concentration increased, ultimately dispersing the CNMs. As reported, suspended CNTs increase with increasing DOM concentration [57]. The loose wrinkles became stacked layers after HA and SMX were loaded on rGO (Fig. S12), consequently decreasing the number of available adsorption sites of CNMs. Meanwhile the ratio of $\mathrm{C}$ and $\mathrm{O}$ also demonstrated the adsorbates adsorbed on rGO. These results also gave the evidence that adsorption 
of SMX on CNMs slowly deceased due to the high coating degree of HA on CNMs, when CNMs were exposed to high HA concentration. For CNMs with completely coating of HA, the adsorption of SMX maybe mainly originate from the free SMX binding with adsorbed HA on CNMs.

\section{Fig.6}

\section{Summary}

The interactions between graphenes and SMX were investigated in comparison with MWCNT10, MWCNT15, MWCNT15-COOH, MWCNT15-OH, and N-doped MWCNT. As shown in this work, rGO had high adsorption affinity for SMX, suggesting that it may strongly alter the transport behavior of SMX through adsorption process. The ${ }^{1} \mathrm{H}$ NMR up-field shift of $-\mathrm{CH}_{3}$ group on SMX verified the $\pi-\pi$ interaction strength as followed the order, pyrene-SMX > phenanthrene-SMX > 9-phenanthrol-SMX > naphthalene-SMX > 3-phenanthrenecarboxylic acid-SMX. It further proved that oxygen-containing groups (e.g. $\mathrm{OH}$ and $\mathrm{COOH}$ ) on the surface of CNMs reduced the $\pi-\pi$ interactions between the graphitic surface and SMX. The morphologies of rGO and MWCNT10 changed from linear to dispersed morphologies, observed by AFM, with increment of HA concentration. It resulted from the varying coating degree of HA on CNMs, which induced the different interaction strength of electrostatic repulsion and steric hindrance of HA. Additionally, adsorbed HA on CNMs could bind with SMX. Therefore, both morphologies changes of CNMs and binding interaction with SMX altered the varying adsorption behavior of SMX in the presence of HA.

\section{Acknowledgements}

This work is supported in part by grants from the Key project from National Science Foundation of China (41430106), National Natural Science Foundation of China (41473096, 41273092, 


\section{References}

404

405

406

407

408

409

[1] Ren W, Cheng H-M. The global growth of graphene. Nat Nano. 2014;9(10):726-30.

[2] Novoselov KS, Falko VI, Colombo L, Gellert PR, Schwab MG, Kim K. A roadmap for graphene. Nature. 2012;490(7419):192-200.

[3] Zurutuza A, Marinelli C. Challenges and opportunities in graphene commercialization. Nat Nano. 2014;9(10):730-4.

[4] Bussy C, Ali-Boucetta H, Kostarelos K. Safety considerations for graphene: lessons learnt from carbon nanotubes. Accounts of Chem. Res. 2013;46(3):692-701.

[5] Li Z, Liu Z, Sun H, Gao C. Superstructured assembly of nanocarbons: fullerenes, nanotubes, and graphene. Chem. Rev. 2015;115(15):7046-117.

[6] Xiao F, Pignatello JJ. $\pi^{+}-\pi$ Interactions between (Hetero)aromatic amine cations and the graphitic surfaces of pyrogenic carbonaceous materials. Environ. Sci. Technol. 2015;49(2):906-14.

[7] Shen X, Guo X, Zhang M, Tao S, Wang X. Sorption mechanisms of organic compounds by carbonaceous materials: site energy distribution consideration. Environ. Sci. Technol. 2015;49(8):4894-902.

[8] Patiño Y, Díaz E, Ordóñez S, Gallegos-Suarez E, Guerrero-Ruiz A, Rodríguez-Ramos I. Adsorption of emerging pollutants on functionalized multiwall carbon nanotubes. Chemosphere. 2015; 136:174-80.

[9] Zhao J, Wang Z, White JC, Xing B. Graphene in the aquatic environment: adsorption, 
dispersion, toxicity and transformation. Environ. Sci. Technol. 2014;48(17):9995-10009.

[10] Maliyekkal SM, Sreeprasad TS, Krishnan D, Kouser S, Mishra AK, Waghmare UV, et al. Graphene: a reusable substrate for unprecedented adsorption of pesticides. Small (Weinheim an der Bergstrasse, Germany). 2013;9(2):273-83.

[11] Iijima S. Helical microtubules of graphitic carbon. Nature. 1991;354(6348):56-8.

[12] Geim AK. Graphene: Status and Prospects. Science. 2009;324(5934):1530-4.

[13]Bianco A, Cheng H-M, Enoki T, Gogotsi Y, Hurt RH, Koratkar N, et al. All in the graphene family - A recommended nomenclature for two-dimensional carbon materials. Carbon. 2013;65:1-6.

[14] Yang K, Xing B. Adsorption of organic compounds by carbon nanomaterials in aqueous phase: polanyi theory and its application. Chem. Rev. 2010;110(10):5989-6008.

[15]Petersen EJ, Zhang L, Mattison NT, O'Carroll DM, Whelton AJ, Uddin N, et al. Potential release pathways, environmental fate, and ecological risks of carbon nanotubes. Environ. Sci. Technol. 2011;45(23):9837-56.

[16] Gottschalk F, Sun T, Nowack B. Environmental concentrations of engineered nanomaterials: Review of modeling and analytical studies. Environ. Pollut. 2013;181(0):287-300.

[17] Thiele-Bruhn S. Pharmaceutical antibiotic compounds in soils - a review. J. Plant Nutr. Soil Sci. 2003;166(2):145-67.

[18]Focazio MJ, Kolpin DW, Barnes KK, Furlong ET, Meyer MT, Zaugg SD, et al. A national reconnaissance for pharmaceuticals and other organic wastewater contaminants in the United States - II) Untreated drinking water sources. Sci. Total Environ. 2008;402(2-3):201-16.

[19]Done HY, Halden RU. Reconnaissance of 47 antibiotics and associated microbial risks in seafood sold in the United States. J. Hazard. Mater. 2015;282:10-7.

[20]Luo Y, Xu L, Rysz M, Wang Y, Zhang H, Alvarez PJJ. Occurrence and transport of tetracycline, sulfonamide, quinolone, and macrolide antibiotics in the Haihe river basin, China. Environ. Sci. Technol. 2011;45(5):1827-33.

[21]Baquero F, Martínez J-L, Cantón R. Antibiotics and antibiotic resistance in water environments. Current Opinion Biotechnol. 2008;19(3):260-5.

[22] Chen H, Gao B, Li H. Removal of sulfamethoxazole and ciprofloxacin from aqueous solutions by graphene oxide. J. Hazard. Mater. 2015;282:201-7. 
[23]Blasioli S, Martucci A, Paul G, Gigli L, Cossi M, Johnston CT, et al. Removal of sulfamethoxazole sulfonamide antibiotic from water by high silica zeolites: A study of the involved host-guest interactions by a combined structural, spectroscopic, and computational approach. J. Colloid Interface Sci. 2014;419(0):148-59.

[24]Ji L, Shao Y, Xu Z, Zheng S, Zhu D. Adsorption of monoaromatic compounds and pharmaceutical antibiotics on carbon nanotubes activated by $\mathrm{KOH}$ etching. Environ. Sci. Technol. 2010;44(16):6429-36.

[25]Pan B, Zhang D, Li H, Wu M, Wang Z, Xing B. Increased adsorption of sulfamethoxazole on suspended carbon nanotubes by dissolved humic acid. Environ. Sci. Technol. 2013;47(14):7722-8.

[26]Hou J, Pan B, Niu X, Chen J, Xing B. Sulfamethoxazole sorption by sediment fractions in comparison to pyrene and bisphenol A. Environ. Pollut. 2010;158(9):2826-32.

[27] Wang C, Li H, Liao S, Zheng H, Wang Z, Pan B, et al. Coadsorption, desorption hysteresis and sorption thermodynamics of sulfamethoxazole and carbamazepine on graphene oxide and graphite. Carbon. 2013;65(0):243-51.

[28]Zhu D, Hyun S, Pignatello JJ, Lee LS. Evidence for $\pi-\pi$ electron donor-acceptor interactions between $\pi$-donor aromatic compounds and $\pi$-acceptor sites in soil organic matter through $\mathrm{pH}$ effects on sorption. Environ. Sci. Technol. 2004;38(16):4361-8.

[29] Wang X, Tao S, Xing B. Sorption and competition of aromatic compounds and humic acid on multiwalled carbon nanotubes. Environ. Sci. Technol. 2009;43(16):6214-9.

[30] Wang F, Shih K, Leckie JO. Effect of humic acid on the sorption of perfluorooctane sulfonate (PFOS) and perfluorobutane sulfonate (PFBS) on boehmite. Chemosphere. 2015;118(0):213-8.

[31]Lerman I, Chen Y, Xing B, Chefetz B. Adsorption of carbamazepine by carbon nanotubes: Effects of DOM introduction and competition with phenanthrene and bisphenol A. Environ. Pollut. 2013;182(0):169-76.

[32] Wang F, Yao J, Chen H, Yi Z, Xing B. Sorption of humic acid to functionalized multi-walled carbon nanotubes. Environmental Pollution. 2013;180(0):1-6.

[33] Wang F, Yao J, Yu C, Chen H, Yi Z, Choi MMF. Mutual effects of dialkyl Phthalate esters and humic acid sorption on carbon nanotubes in aqueous environments. ACS Sustain. Chem. Eng. 2014;2(5):1219-27. 
[34] Gauthier TD, Shane EC, Guerin WF, Seitz WR, Grant CL. Fluorescence quenching method for determining equilibrium constants for polycyclic aromatic hydrocarbons binding to dissolved humic materials. Environ. Sci. Technol. 1986;20(11):1162-6.

[35] Wang F, Yao J, Sun K, Xing B. Adsorption of dialkyl phthalate esters on carbon nanotubes. Environ. Sci. Technol. 2010;44(18):6985-91.

[36] Chanda D, Hnat J, Dobrota AS, Pasti IA, Paidar M, Bouzek K. The effect of surface modification by reduced graphene oxide on the electrocatalytic activity of nickel towards the hydrogen evolution reaction. Phys. Chem. Chem. Phys. 2015;17(40):26864-74.

[37] Keith EW. Reversible graphene functionalization for electronic applications: a review. the science and function of nanomaterials: from synthesis to application: American Chemical Society 2014, p. 41-54.

[38] Wang J, Chen Z, Chen B. Adsorption of polycyclic aromatic hydrocarbons by graphene and graphene oxide nanosheets. Environ. Sci. Technol. 2014;48(9):4817-25.

[39] Amir S, Jouraiphy A, Meddich A, El Gharous M, Winterton P, Hafidi M. Structural study of humic acids during composting of activated sludge-green waste: Elemental analysis, FTIR and ${ }^{13}$ C NMR. J. Hazard. Mater. 2010;177(1-3):524-9.

[40]Pei Z, Li L, Sun L, Zhang S, Shan X-q, Yang S, et al. Adsorption characteristics of 1,2,4-trichlorobenzene, 2,4,6-trichlorophenol, 2-naphthol and naphthalene on graphene and graphene oxide. Carbon. 2013;51:156-63.

[41] Sun Y, Yang S, Chen Y, Ding C, Cheng W, Wang X. Adsorption and desorption of U(VI) on functionalized graphene oxides: a combined experimental and theoretical study. Environ. Sci. Technol. 2015;49(7):4255-62.

[42] Chen X, Chen B. Macroscopic and spectroscopic investigations of the adsorption of nitroaromatic compounds on graphene oxide, reduced graphene oxide, and graphene nanosheets. Environ. Sci. Technol. 2015;49(10):6181-9.

[43] Wang X, Qin Y, Zhu L, Tang H. Nitrogen-doped reduced graphene oxide as a bifunctional material for removing bisphenols: synergistic effect between adsorption and catalysis. Environ. Sci. Technol. 2015;49(11):6855-64.

[44] Sheng Z-H, Shao L, Chen J-J, Bao W-J, Wang F-B, Xia X-H. Catalyst-free synthesis of nitrogen-doped graphene via thermal annealing graphite oxide with melamine and its excellent 
electrocatalysis. ACS Nano. 2011;5(6):4350-8.

[45] Sui Z-Y, Meng Y-N, Xiao P-W, Zhao Z-Q, Wei Z-X, Han B-H. Nitrogen-doped graphene aerogels as efficient supercapacitor electrodes and gas adsorbents. ACS Appl. Mater. Interfaces. 2015;7(3):1431-8.

[46] Carter MC, Kilduff JE, Weber WJ. Site energy distribution analysis of preloaded adsorbents. Environ. Sci. Technol. 1995;29(7):1773-80.

[47]Apul OG, Karanfil T. Adsorption of synthetic organic contaminants by carbon nanotubes: A critical review. Water Res. 2015;68(0):34-55.

[48] Xu Z, Buehler MJ. Geometry controls conformation of graphene sheets: membranes, ribbons, and scrolls. ACS Nano. 2010;4(7):3869-76.

[49] Strachowski P, Bystrzejewski M. Comparative studies of sorption of phenolic compounds onto carbon-encapsulated iron nanoparticles, carbon nanotubes and activated carbon. Colloids and Surfaces A: Phys. Eng. Asp. 2015;467(0):113-23.

[50]Bai S, Shen X, Zhu G, Yuan A, Zhang J, Ji Z, et al. The influence of wrinkling in reduced graphene oxide on their adsorption and catalytic properties. Carbon. 2013;60:157-68.

[51]Pan B, Lin D, mashayekhi H, Xing B. Adsorption and hysteresis of bisphenol A and 17 $\alpha$-ethinyl estradiol on carbon nanomaterials. Environ. Sci. Technol. 2008;42:5480-5.

[52]Zhang D, Pan B, Zhang H, Ning P, Xing B. Contribution of different sulfamethoxazole species to their overall adsorption on functionalized carbon nanotubes. Environ Sci Technol. 2010;44(10):3806-11.

[53] Chen J, Chen W, Zhu D. Adsorption of nonionic aromatic compounds to single-walled carbon nanotubes- effects of aqueous solution chemistry. Environ Sci Technol. 2008;42:7225-30.

[54]Ji L, Chen W, Zheng S, Xu Z, Zhu D. Adsorption of sulfonamide antibiotics to multiwalled carbon nanotubes. Langmuir. 2009;25(19):11608-13.

[55] Yu F, Ma J, Han S. Adsorption of tetracycline from aqueous solutions onto multi-walled carbon nanotubes with different oxygen contents. Sci. Rep. 2014;4:5326.

[56] Yang S, Li L, Pei Z, Li C, Shan X-q, Wen B, et al. Effects of humic acid on copper adsorption onto few-layer reduced graphene oxide and few-layer graphene oxide. Carbon. 2014;75:227-35.

[57] Smith B, Yang J, Bitter JL, Ball WP, Fairbrother DH. Influence of surface oxygen on the 
543 interactions of carbon nanotubes with natural organic matter. Environ. Sci. Technol. 2012;46(23):12839-47.

545

546

547

548

549

550

551

552

553

554

555

556

557

558

559

560

561

562

563

564

565

566

567

568

569

570

571

572

573 


\section{List of captions for Table and Figures.}

Table 1. Langmuir and Freundlich model fitting parameters for adsorption of SMX by carbonaceous nanomaterials

Fig. 1. The SEM/EDX images of reduced graphene oxide (rGO), graphene oxide (GO) and graphene nanoplatelets pastes (GNP).

Fig. 2. C 1s XPS spectra of rGO, GO, GNP, MWCNT10, MWCNT15, MWCNT15-OH, MWCNT15-COOH, and N-doped MWCNTs.

Fig. 3. Adsorption isotherms of SMX onto rGO, GO, GNP, MWCNT10, MWCNT15, MWCNT15-OH, MWCNT15-COOH, and N-doped MWCNTs.

Fig. 4. ${ }^{1} \mathrm{H}$ nuclear magnetic resonance (NMR) chemical shifts $(\delta)$ of the $-\mathrm{CH}_{3}$ group on $\mathrm{SMX}$ $(0.01 \mathrm{M})$ vs the concentration of $\pi$-donors naphthalene (NAPH), phenanthrene (PHEN), pyrene (PYR), 9-phenanthrol, 3-phenanthrenecarboxylic acid in methanol- $d_{4}$.

Fig. 5. Effect of humic acid (HA) on the adsorption of SMX (7 mg/L) on rGO, GO, GNP, MWCNT10, MWCNT15, MWCNT15-OH, MWCNT15-COOH, and N-doped MWCNTs.

Fig. 6. AFM images of rGO and MWCNT10 in aquatic environment. 
600

601 602

Table 1.

Langmuir and Freundlich model fitting parameters for adsorption of SMX by carbonaceous nanomaterials

\begin{tabular}{llllllll}
\hline & \multicolumn{2}{l}{ Langmuir model } & \multicolumn{2}{l}{ Freundlich model } \\
& $q_{\max }$ & $K_{\mathrm{L}}$ & $r^{2}$ & $K_{\mathrm{f}}$ & $n$ & $r^{2}$ & $\begin{array}{c}K_{\mathrm{d}} \\
\left(C_{\mathrm{e}}=2 \mathrm{mg} / \mathrm{L}\right)\end{array}$ \\
\hline rGO & $11.76 \pm 1.31$ & $0.21 \pm 0.04$ & 0.973 & $11.37 \pm 0.36$ & $0.53 \pm 0.02$ & 0.994 & 8.21 \\
\hline GO & $0.15 \pm 0.02$ & $0.01 \pm 0.01$ & 0.956 & $0.19 \pm 0.03$ & $0.87 \pm 0.07$ & 0.960 & 0.17 \\
\hline GNP & $0.08 \pm 0.01$ & $-0.005 \pm 0.006$ & 0.972 & $0.07 \pm 0.02$ & $1.06 \pm 0.08$ & 0.973 & 0.07 \\
MWCNT10 & $3.03 \pm 0.52$ & $0.11 \pm 0.04$ & 0.938 & $3.70 \pm 0.29$ & $0.59 \pm 0.04$ & 0.976 & 2.78 \\
MWCNT15 & $1.01 \pm 0.06$ & $-0.01 \pm 0.004$ & 0.992 & $1.02 \pm 0.1$ & $1.03 \pm 0.04$ & 0.992 & 1.04 \\
MWCNT15-OH & $0.79 \pm 0.06$ & $-0.01 \pm 0.005$ & 0.989 & $0.34 \pm 0.07$ & $1.39 \pm 0.08$ & 0.983 & 0.45 \\
MWCNT15-COOH & $0.54 \pm 0.04$ & $-0.03 \pm 0.003$ & 0.990 & $0.83 \pm 1.03$ & $1.03 \pm 0.05$ & 0.987 & 0.89 \\
N-doped MWCNT & $0.58 \pm 0.04$ & $0.07 \pm 0.01$ & 0.986 & $0.70 \pm 0.06$ & $0.68 \pm 0.04$ & 0.980 & 0.56 \\
\hline
\end{tabular}

603

604

605

606

607

608

609

610

611

612

613

614

615

616

617

618

619

620

621

622

623

624

625

626 

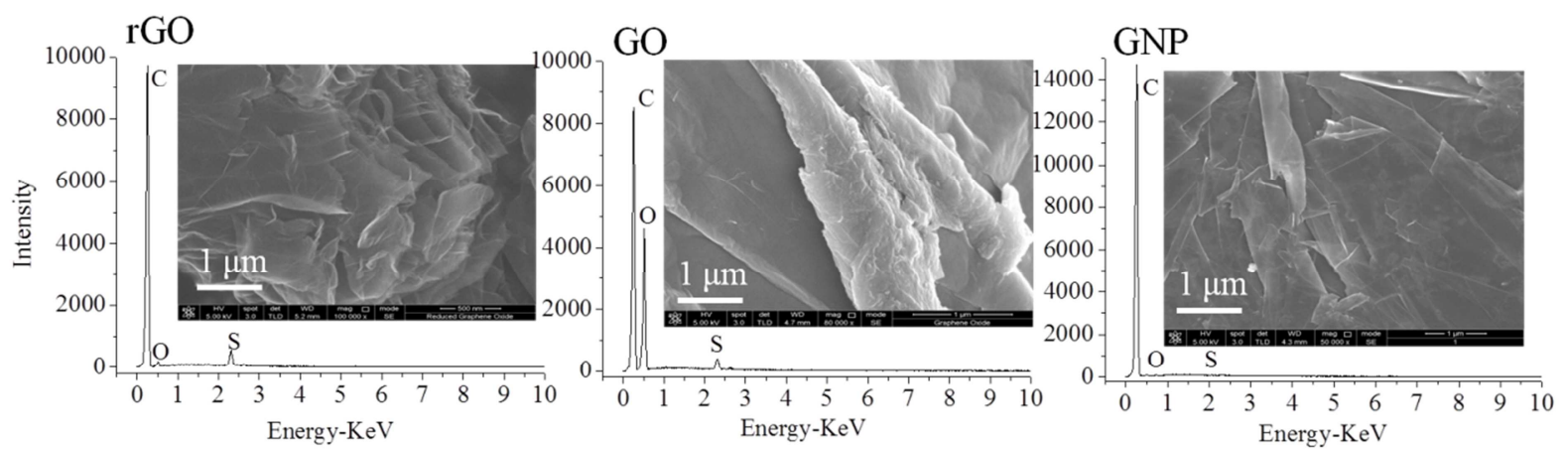

627

628

629 Fig. 1. The SEM/EDX images of reduced graphene oxide (rGO), graphene oxide (GO) and

630 graphene nanoplatelets pastes (GNP).

631

632

633

634

635

636

637

638

639

640

641

642

643

644

645

646 

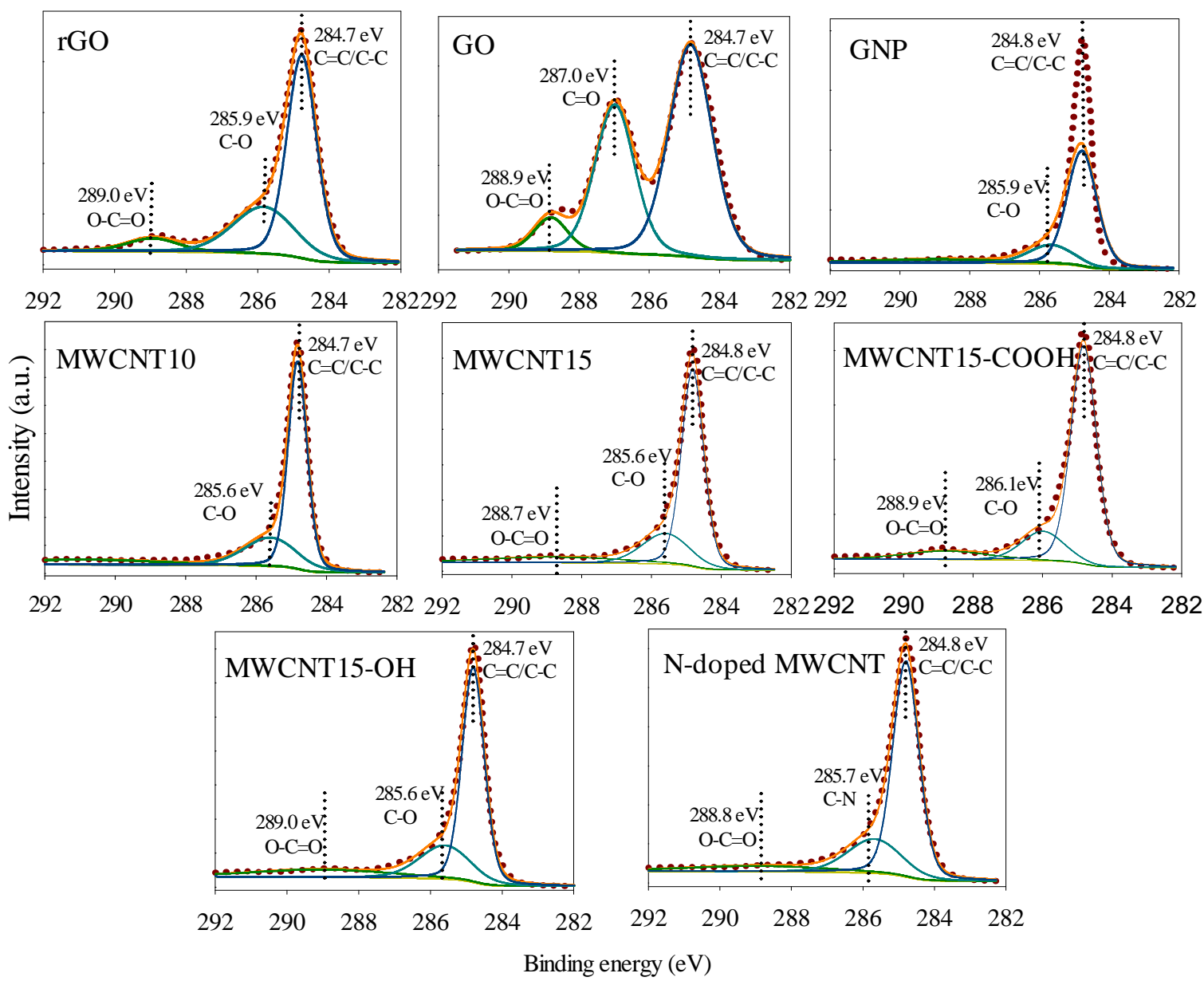

647 Binding energy $(\mathrm{eV})$

648 Fig. 2. C 1s XPS spectra of rGO, GO, GNP, MWCNT10, MWCNT15, MWCNT15-OH, 649 MWCNT15-COOH, and N-doped MWCNTs.

650

651 


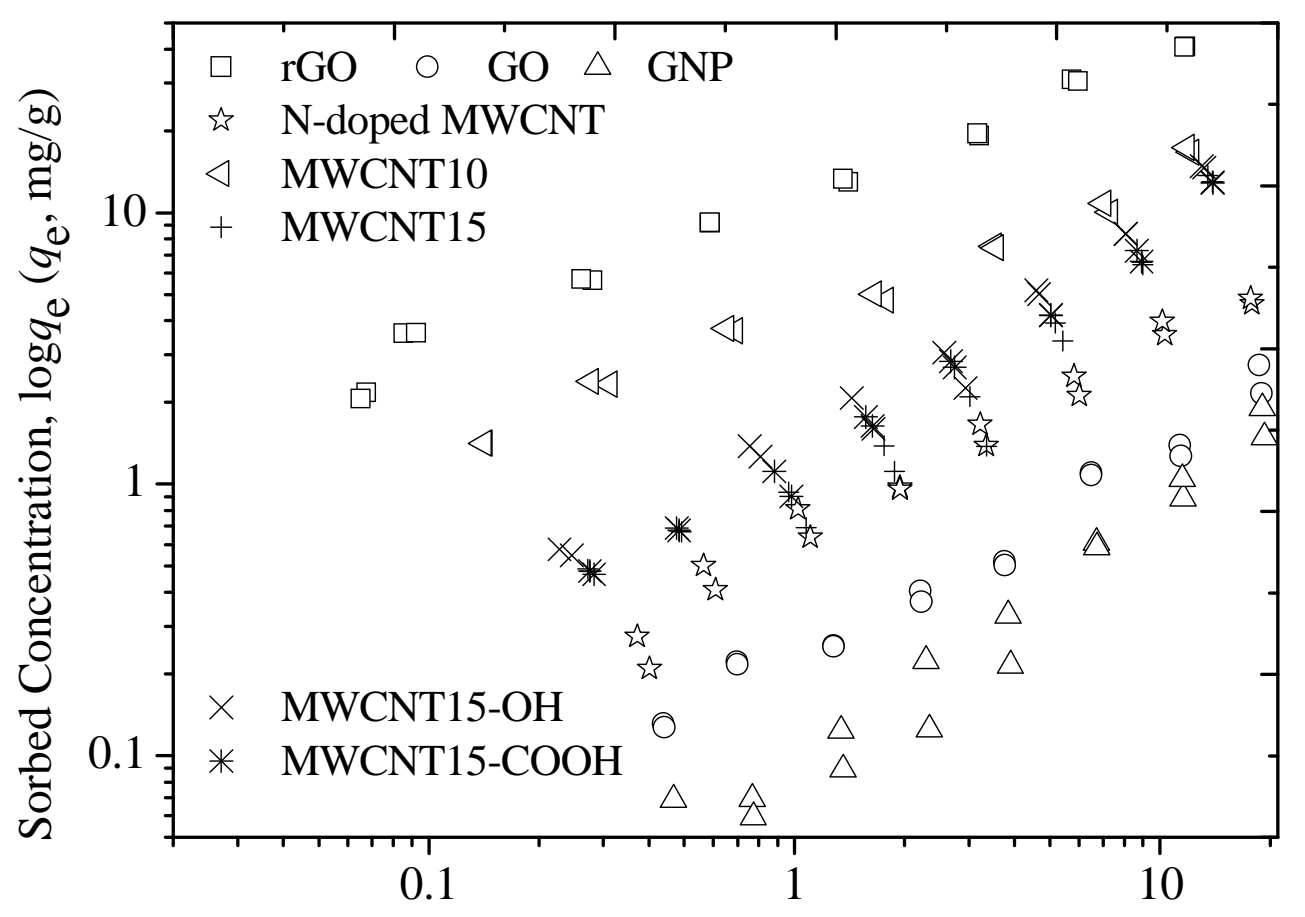

Equilibrium Concentration, $\log C_{\mathrm{e}}\left(C_{\mathrm{e}}, \mathrm{mg} / \mathrm{L}\right)$

654 Fig. 3. Adsorption isotherms of SMX onto rGO, GO, GNP, MWCNT10, MWCNT15, 655 MWCNT15-OH, MWCNT15-COOH, and N-doped MWCNTs. The $q_{\mathrm{e}}(\mathrm{mg} / \mathrm{g})$ is the solid-phase 656 concentration and $C_{\mathrm{e}}(\mathrm{mg} / \mathrm{L})$ is the equilibrium concentration. 


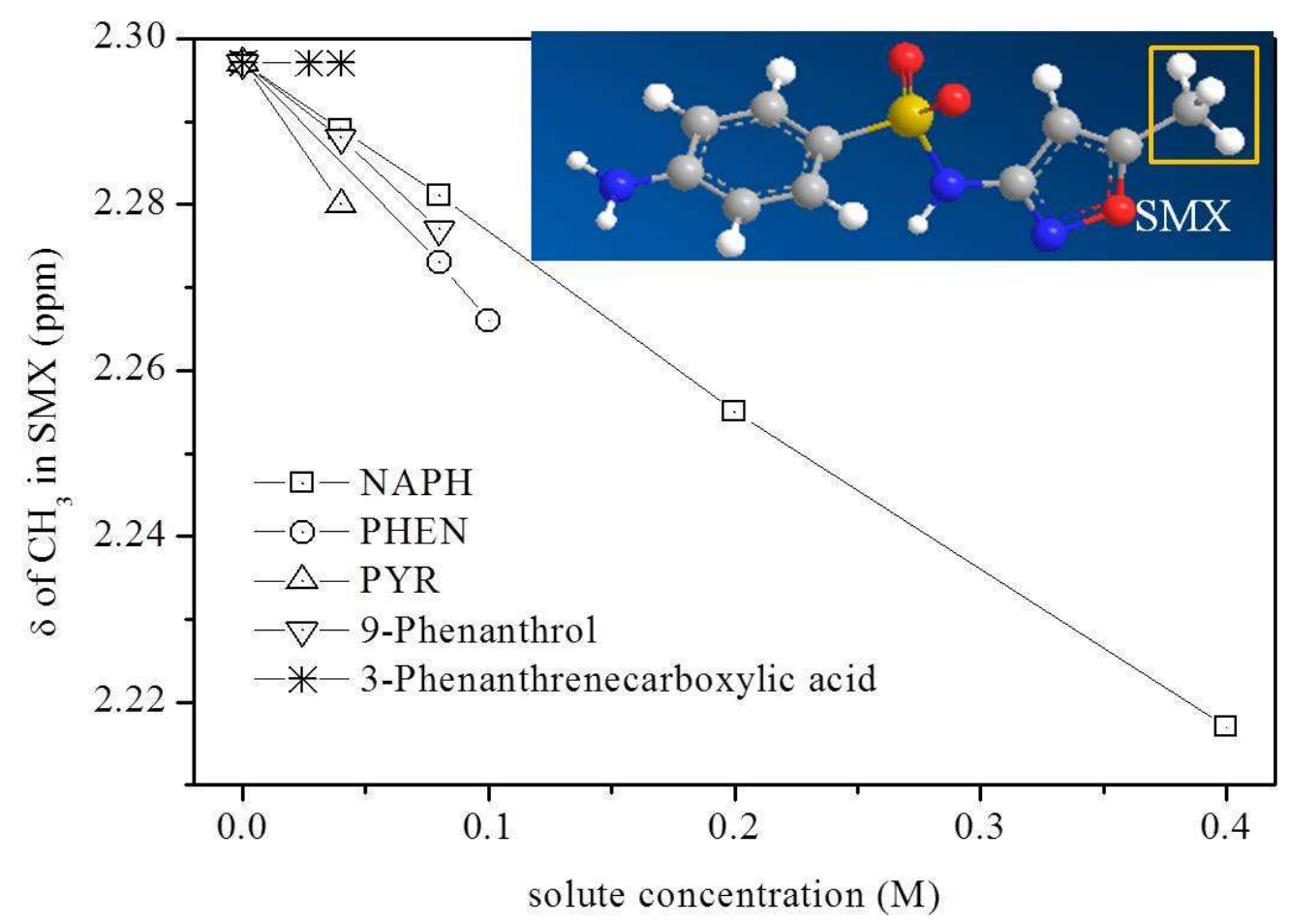

658

659 Fig. 4. ${ }^{1} \mathrm{H}$ nuclear magnetic resonance $(\mathrm{NMR})$ chemical shifts $(\delta)$ of the $-\mathrm{CH}_{3}$ group on $\mathrm{SMX}$ $660(0.01 \mathrm{M})$ vs the concentration of $\pi$-donors naphthalene (NAPH), phenanthrene (PHEN), pyrene 661 (PYR), 9-phenanthrol, 3-phenanthrenecarboxylic acid in methanol- $d_{4}$.

662

663 


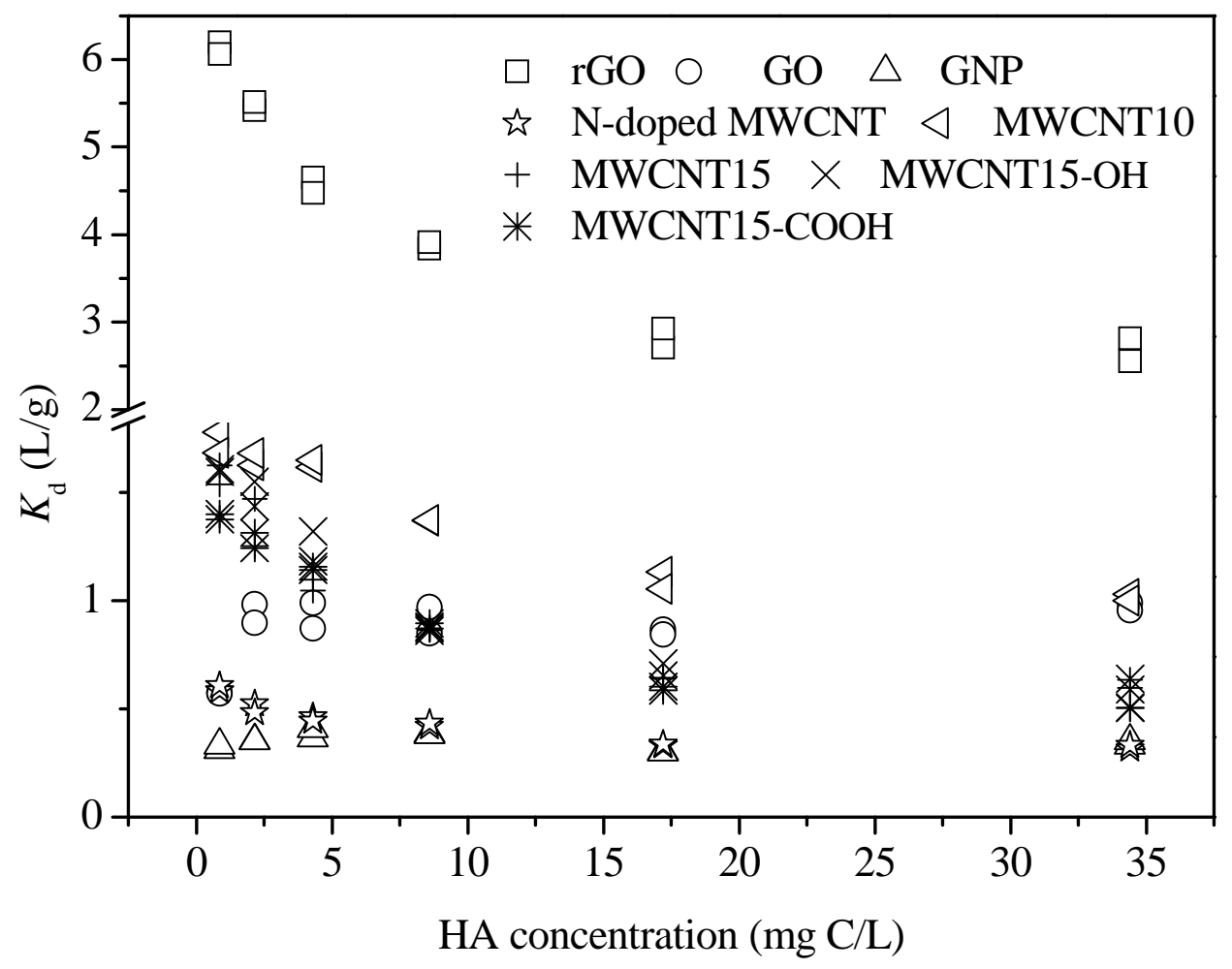

664

665 Fig. 5. Effect of humic acid (HA) on the adsorption of SMX (7 mg/L) on rGO, GO, GNP, 666 MWCNT10, MWCNT15, MWCNT15-OH, MWCNT15-COOH, and N-doped MWCNTs.

667 

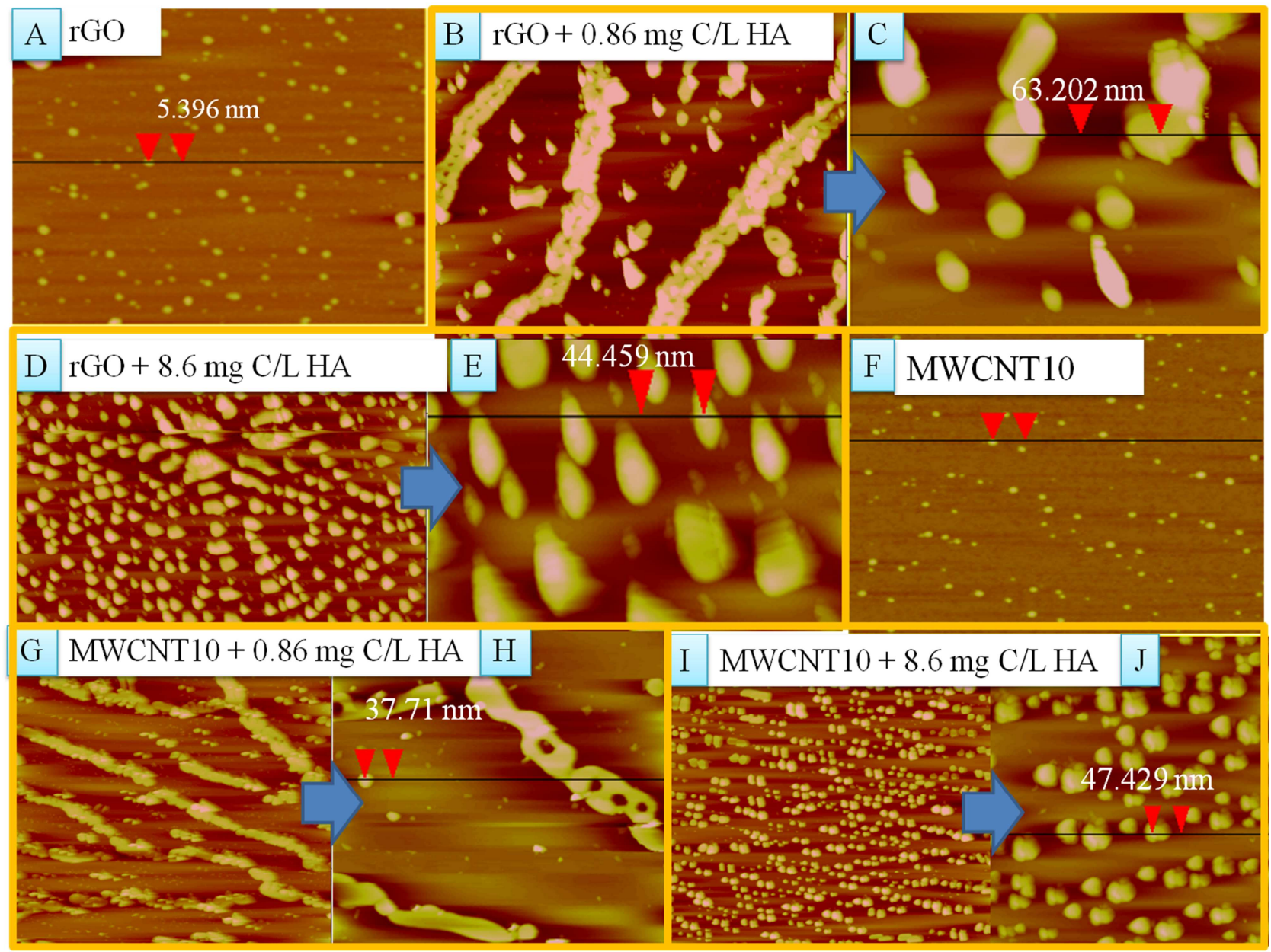

670 Fig. 6. AFM images of rGO and MWCNT10 in aquatic environment. (A) rGO, (B and C) rGO +

$6710.86 \mathrm{mgC} / \mathrm{L} \mathrm{HA}+7 \mathrm{mg} / \mathrm{L} \mathrm{SMX}$, (D and E) rGO + $8.6 \mathrm{mgC} / \mathrm{L} \mathrm{HA}+7 \mathrm{mg} / \mathrm{L} \mathrm{SMX}$, (F) MWCNT10,

672 (G and H) MWCNT10 + 0.86 mgC/L HA + 7 mg/L SMX, (I and J) MWCNT10 + 8.6 mgC/L HA + $6737 \mathrm{mg} / \mathrm{L}$ SMX. 


\section{Graphical Abstract}

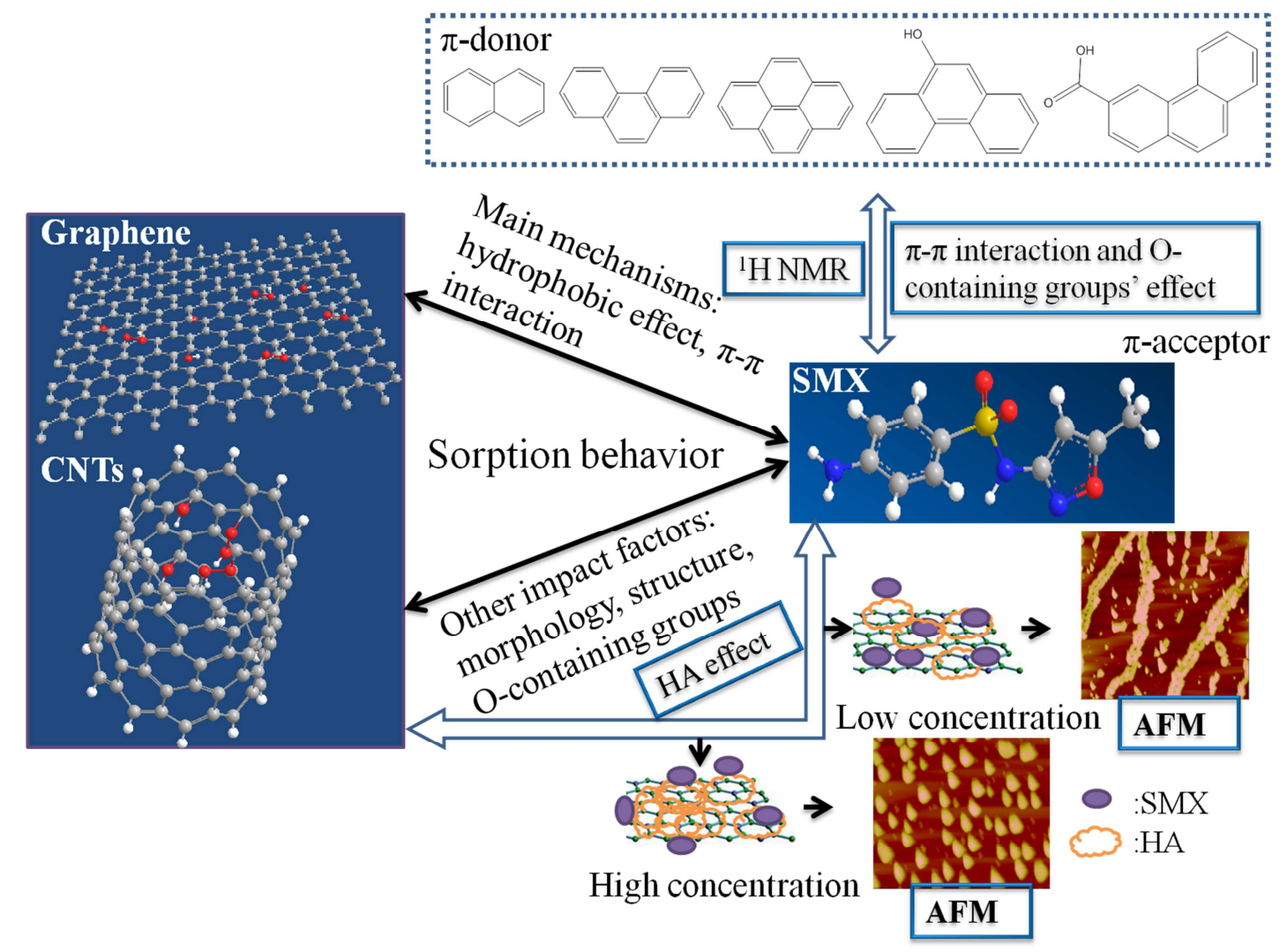

